\title{
WET AND DRY DEPOSITION OF PHOSPHORUS INTO LAKE HURON
}

\author{
R. G. DELUMYEA* and R. L. PETEL** \\ Great Lakes Research Division, The University of Michigan, Ann Arbor, MI 48109 U.S.A.
}

(Received 23 January, 1978; revised 25 May, 1978)

\begin{abstract}
The deposition rates for wet, dry, and integrated fallout of $\mathrm{P}$ to the southern portion of Lake Huron were determined. Samples were analyzed for water-soluble, acid $(\mathrm{pH}=2)$ soluble, and insoluble (bound) $\mathbf{P}$. The term 'available $\mathbf{P}$ ' was used to indicate the sum of the water- and acid-soluble fractions of $P$ in each type of input. Of the integrated fallout samples, approximately one-third was present as available $P$. The deposition rate for dry fallout of available $\mathrm{P}$ was determined to be $1.7 \mathrm{ng} \mathrm{cm}^{-2}$ day-1. The wet deposition rate was estimated to be $2.2 \mathrm{ng} \mathrm{cm} \mathrm{cm}^{-2} \mathrm{day}^{-1}$ for available $P$. Total fallout of available $P$, determined from

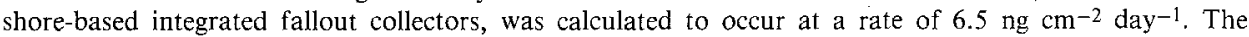
difference between the wet-plus-dry deposition and the integrated deposition rates has been ascribed to the contamination of integrated fallout collectors by local sources (roads, agricultural activity, etc.) though attempts were made to minimize this problem. The presence of large quantities of biological material (pollen, algae, insect larvae) accounted for a large fraction of the difference observed, especially in the spring months.
\end{abstract}

\section{Introduction}

Phosphorus has been determined as being the limiting nutrient in the Great Lakes system (Schelske and Stoermer, 1971; Miller et al., 1974). The three major natural inputs to Lake Huron are the runoff of groundwater and rivers, the inflow of the upper lakes (Michigan and Superior) and atmospheric deposition. The atmospheric input of water (rain and snow) has been estimated to be $54 \%$ by volume for Lake Superior and $32 \%$ for Lake Huron (Elder, 1975). Such relatively large contributions from the atmosphere are due to the large percentage of the lake surface of the basin areas. Thus the input of nutrients such as $\mathrm{P}$ and contaminants from the atmosphere (e.g. $\mathrm{Pb}$ ) can be expected to be significant as well. For example, it has been estimated that atmospheric inputs may account for up to $50 \%$ of the $\mathrm{P}$ and $\mathrm{N}$ entering Lake Superior (Elder, 1975) and a study of the $P$ content of precipitation in the southern portion of Lake Michigan, (Murphy, 1974) indicated that wet deposition alone accounts for 20 to $33 \%$ of the available $P$ entering the Lake. If the input due to dry fallout had been considered, this value would have been significantly higher.

It should be noted that all of the $\mathrm{P}$ entering the lake from the air must pass through the layer of maximum biological activity (euphotic zone). This is not true of river inputs or the inflow from the upper lakes. Further, since dissolved $\mathrm{P}$ in rain provides an immediate but intermittent source of nutrient to the biomass whereas dry fallout

Present address: *Department of Chemistry, Washington University, St. Louis, MO 63130 U.S.A. (Author to whom correspondence may be addressed.) **Health Physics Research Division, Philippines Atomic Energy Commission, Don Mariano Marcos Avenue, Diliman, Quezon City, Philippines. 
provides a continuous source, the effect of each type of atmospheric input must be evaluated independently. The present study (Delumyea and Petel, 1977) was undertaken to determine the total input of $\mathbf{P}$ to Lake Huron from the atmosphere. The relative inputs due to wet and dry deposition were compared. Since the chemical form of the $\mathrm{P}$ determines its immediate effect on the quality of the lake, water-soluble, acidsoluble $(\mathrm{pH}=2)$ and total $\mathrm{P}$ were determined. The term 'soluble' will be used to refer to water-soluble $\mathrm{P}$, 'reactive' to refer to acid-soluble $\mathrm{P}$, and 'available' to the sum of these two fractions of the total $\mathrm{P}$. The remainder of the $\mathrm{P}$ is insoluble or 'bound'.

\section{Sampling}

Eleven land-based stations, shown in Figure 1, were equipped with a 5-m mast. An integrated fallout collector was placed at each station for the period between aerosol sample collections, generally 24 to 30 days. These collectors consisted of a 1 gal Nalgene ${ }^{\mathrm{R}}$ bottle with the bottom $25 \mathrm{~mm}$ cut off, inverted and attached to an upright $1 \mathrm{gal}$ bottle. A polyethylene sleeve was placed around the contact and secured with fiber-reinforced tape. A 17.5 mesh nylon screen was placed over the opening to reduce contamination from large objects (leaves, insects, etc.); however, such contamination

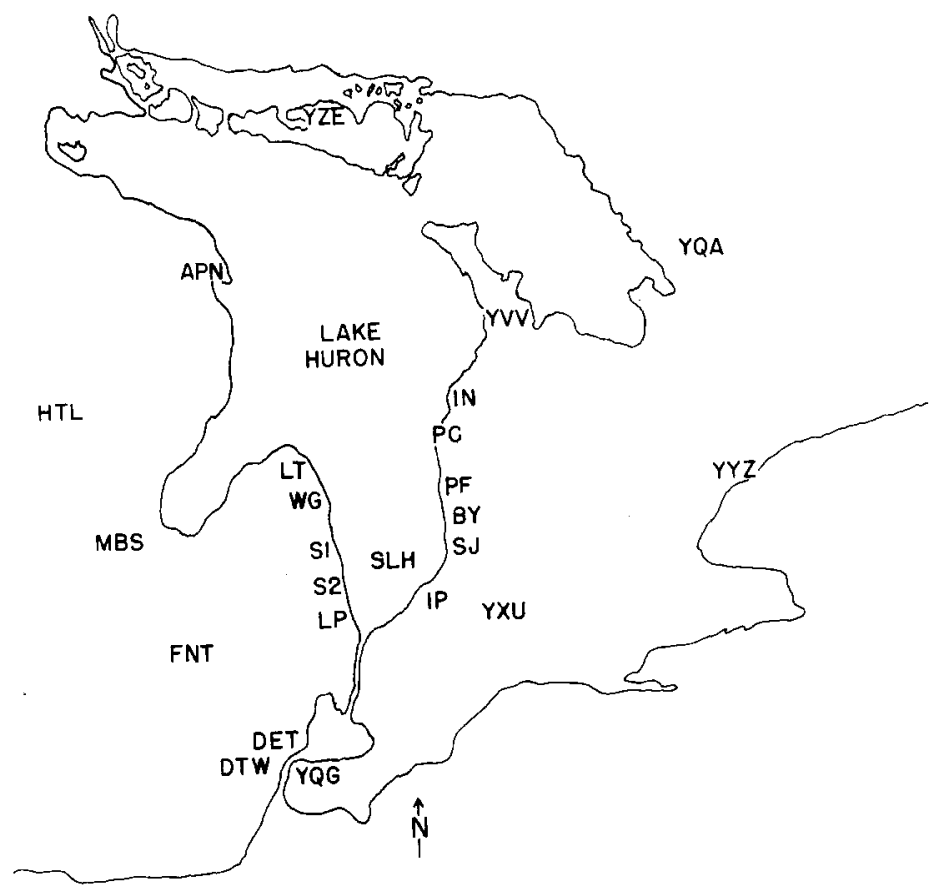

Fig. 1. Location of sampling and meteorological stations. Two-letter codes designate sampling stations on the Lake Huron shore and three-letter codes indicate weather stations. 
may have occurred due to leaching of $P$ from objects which remained on the screen, particularly during rain or snow episodes. Immediately prior to placement, $50 \mathrm{ml}$ $\mathrm{H}_{2} \mathrm{SO}_{4}$ of $\mathrm{pH}=2$ was added to the container as a biocide and preservative. The unit was then placed in a wood-and-metal holder and hoisted to the top of the 5-m mast. During a five day period each month, the integrated fallout collectors were replaced by aerosol collection equipment. Gelman Air Sampling Kits, modified for field use, were installed at each station to collect aerosol samples on $37-\mathrm{mm}$ glass fiber filters in holders placed inside downward-facing plastic rain shields.

The Gelman pumps were also used to draw air through downward-facing Andersen cascade impactors onto discs of $0.1-\mathrm{mm}$ Durethane ${ }^{\mathrm{R}}$. A Whatman 41 backup filter in an in-line filter holder was attached to the end of the impactor. A flow rate of approximately $28 \mathrm{lpm}$ was used, and samples were collected for $24 \mathrm{~h}$ periods. High volume air samplers (General Metal Works, 8368 Bridgetown Rd., Cleves, OH) were used to collect aerosol particles on $20.3 \times 25.4 \mathrm{~cm}$ glass fiber mats, weighed to constant weight before and after sample collection to determine the total weight gained through aspiration of a known volume of air. These samplers were run at $1400 \mathrm{lpm}$ for 8 to 12 and sometimes $24 \mathrm{~h}$ periods. Sections of the filter mat were also cut with a $37 \mathrm{~mm}$ diameter stainless steel cutter and chemically analyzed for P content. The Gelman samplers were run for $8 \mathrm{~h}$ periods followed by a $4 \mathrm{~h}$ down-time during which flow rate and vacuum pressure were recorded and new filters installed. The pumps were activated by a timing device to run from 1000 to $1800 \mathrm{~h}$ and from 2200 to $0600 \mathrm{~h}$ the following day.

During this five day period, event rain samples were collected in $0.7-\mathrm{m}$ diameter rain buckets lined with polyethylene bags. The buckets were placed out when rain was anticipated and removed as soon after the event as possible (usually less than $8 \mathrm{~h}$ ). The contents of the bag were agitated to mix the sample of which a portion was transferred to a $500 \mathrm{ml}$ polyethylene bottle. Rainfall data supplied by weather service stations in the basin area were used to determine the amount of rainfall which occurred as explained below.

The research vessel Roger $R$. Simons was scheduled to anchor on station in Lake Huron for one $24 \mathrm{~h}$ period each month from April through October 1975. While on station the ship was anchored at the bow and only one generator was run, to reduce the possibility of contamination from ship exhaust. Samples which appeared excessively black, or which were collected when the ship-board windvane indicated a windspeed less than $5 \mathrm{~km} \mathrm{~h}^{-1}$ were excluded from the data set. During this period, one $24 \mathrm{~h}$ HiVol sample, two simultaneous $24 \mathrm{~h}$ Andersen samples (one for future trace metal analysis, one for analysis for $\mathrm{P}$ ) and three consecutive pairs of $8 \mathrm{~h}$ Gelman Samples (one set on Whatman 41 for metal analysis, the other set on glass fiber for phosphate) were collected. Event rain samples were collected when possible.

\subsection{SAMPLE PREPARATION AND CHEMICAL ANALYSIS}

Phosphorus was measured as orthophosphate using a molybdenum-antimony-ascorbate procedure (Murphy and Riley, 1962). This standard heteropolyacid method was 
automated with a Technicon ${ }^{\mathrm{R}}$ AutoAnalyzer II. A volume of approximately $1.6 \mathrm{ml}$ was analyzed from each sample. Blank solutions and standards containing $\mathrm{H}_{2} \mathrm{SO}_{4}$ of $\mathrm{pH}=2$ were run during the analysis of the water and acid filter extracts, event rains and integrated fallout samples. The persulfate digestion for bound or total $\mathbf{P}$ procedures was a modification of the method of Menzel and Corwin (1965); digestion blanks and standards were analyzed with the digested samples.

Singly distilled water was used in the preparation of all reagents, for extraction of the filters and dilution of samples. The concentration of $\mathbf{P}$ in the water was routinely monitored and found to be less than $2 \%$ of the sample blank. For extraction, a glass fiber filter was placed in a $60 \mathrm{ml}$ sintered glass funnel. Ten $2 \mathrm{ml}$ volumes of distilled water were aspirated through the filter under slightly negative pressure. The filtrate was quantitatively transferred to a $25 \mathrm{ml}$ volumetric flask containing 2 drops of concentrated $\mathrm{H}_{2} \mathrm{SO}_{4}$ and diluted to volume with distilled water. The extraction was then repeated using ten $2 \mathrm{ml}$ aliquots of $\mathrm{H}_{2} \mathrm{SO}_{4}$ of $\mathrm{pH}=2$. This filtrate was transferred to a $25 \mathrm{ml}$ volumetric flask (no acid present) and diluted to volume with $\mathrm{pH}=2$ solution. The first extraction was analyzed for water-soluble $\mathrm{P}$, the second for acid-soluble $P$.

Monthly integrated fallout samples were acidified during collection and therefore water-soluble $P$ values were not obtained. After measurement of the total volume collected, the samples were filtered through glass fiber filters to obtain available $\mathbf{P}$ values. Portions were filtered through presoaked $0.4 \mu \mathrm{m}$ Millipore filters to determine total dissolved $P$, and $25.0 \mathrm{ml}$ of the original samples were digested to determine total $P$ content.

Event rains were analyzed 'as is" without filtration or acidification. It was later realized that for the sake of comparison, the rain samples should have been acidified to determine whether additional (but not water-soluble) $\mathrm{P}$ would be available for uptake. The sample collection and analysis scheme is summarized in Table I.

Meterological data were supplied by the National Weather Service Forecast Office at Detroit Metropolitan Airport, Detroit, Mich. Teletype outputs of the Service A reports, consisting of hourly observations of temperature, dew point, wind speed, wind direction, precipitation, and cloud cover, were provided for all Michigan and Ontario weather stations. Similar data were obtained on the Roger S. Simons when it was stationed on the lake.

TABLE I

Collection and analysis scheme

\begin{tabular}{llllll}
\hline Collection & \multicolumn{5}{c}{ Analysis } \\
\cline { 1 - 2 } $\begin{array}{llll}\text { Sample } \\
\text { type }\end{array}$ & $\begin{array}{l}\text { Time } \\
\text { period, }\end{array}$ & $\begin{array}{l}\text { No. days } \\
\text { per month }\end{array}$ & $\begin{array}{l}\text { Soluble } \\
\text { (water) } \mathrm{P}\end{array}$ & $\begin{array}{l}\text { Reactive } \\
\left(\mathrm{pH}=2 \mathrm{H}_{2} \mathrm{SO}_{4}\right) \mathrm{P}\end{array}$ & $\begin{array}{l}\text { Total } \\
\text { (digested) } \mathrm{P}\end{array}$ \\
\hline integrated & 24 & 25 & & $\times$ & $\times$ \\
dry & $2 \times 8$ & 5 & $\times$ & $\times$ & $\times$ \\
wet & variable & event & $\times$ & & $\times$ \\
\hline
\end{tabular}




\section{Results and Discussions}

\subsection{TOTAL FALLOUT}

Integrated fallout or 'bulk' samplers collect both wet and dry deposition which has occurred over a over a fixed area at a particular point during a given period. These samples are subject to a number of errors including the possibility of incomplete retention of dry deposition due to low catch efficiency or re-entrainment of particles near the top of the sampler, evaporation of water and other volatile substances, and contamination from soil, trees, roads, or population centers. Nevertheless, such samplers have been used to estimate the total deposition of many species from the atmosphere (International Joint Commission Report, 1977). To reduce potential contamination in the present study, a screen was placed over the opening, the collector contained a restriction between the open surface and the storage bottle to reduce evaporation, sulfuric acid was added as a biocide, and the screen and walls were washed down with $\mathrm{H}_{2} \mathrm{SO}_{4}(\mathrm{pH}=2)$ after the collection period. For determining integrated fallout inputs, the mean value of the 11 stations at a $90 \%$ confidence limit was used. The $90 \%$ confidence limit was selected as the indicator of statistical reliability and will be indicated whenever possible.

Since the samplers contained $\mathrm{H}_{2} \mathrm{SO}_{4}$ as a preservative and biocide, the water soluble portion of the $\mathrm{P}$ in the sample was not determined; however, available $\mathrm{P}$ was determined on aliquots of the acidified sample after filtration through glass-fiber and/or Millipore filters to remove suspended particulate matter. The efficiency of this filtration was verified by digestion of part of the filtrate and subsequent comparison of the $\mathrm{P}$ content of the digested and undigested filtrate, which showed that no additional $P$ was present in the digested samples. Due to complications in the digestion procedure, total $\mathrm{P}$ values were obtained only for August-December integrated samples. Comparison of available and total $\mathrm{P}$ in the integrated samples indicated that $32 \pm 18 \%(n=24)$ of the total $P$ in these late fall samples was present as available. Volumes collected in these samples were checked against weather service data on total rainfall and significant losses due to evaporation were observed during the summer months. Thus, amounts of available $P$ rather than concentrations were used for comparison.

Average $P$ contents of the samples were plotted (Figure 2) to illustrate the seasonal variation of total available $P$ input from the atmosphere. This input peaked in the late spring and rose again in early fall in a pattern that roughly corresponds to agricultural activity in the Lake Huron basin. The May-June samples also showed marked evidence of biological activity despite the screen and biocide. Most of the samples for this period were dark green or yellow, and microscopic examination showed algae growth, pollen, and even small insect larvae. A significant amount of the $\mathrm{P}$ input during this period was therefore due to biological activity. In future studies, a stronger biocide is recommended.

The desposition rate for total fallout was determined by dividing the amount of $\mathrm{P}$ 


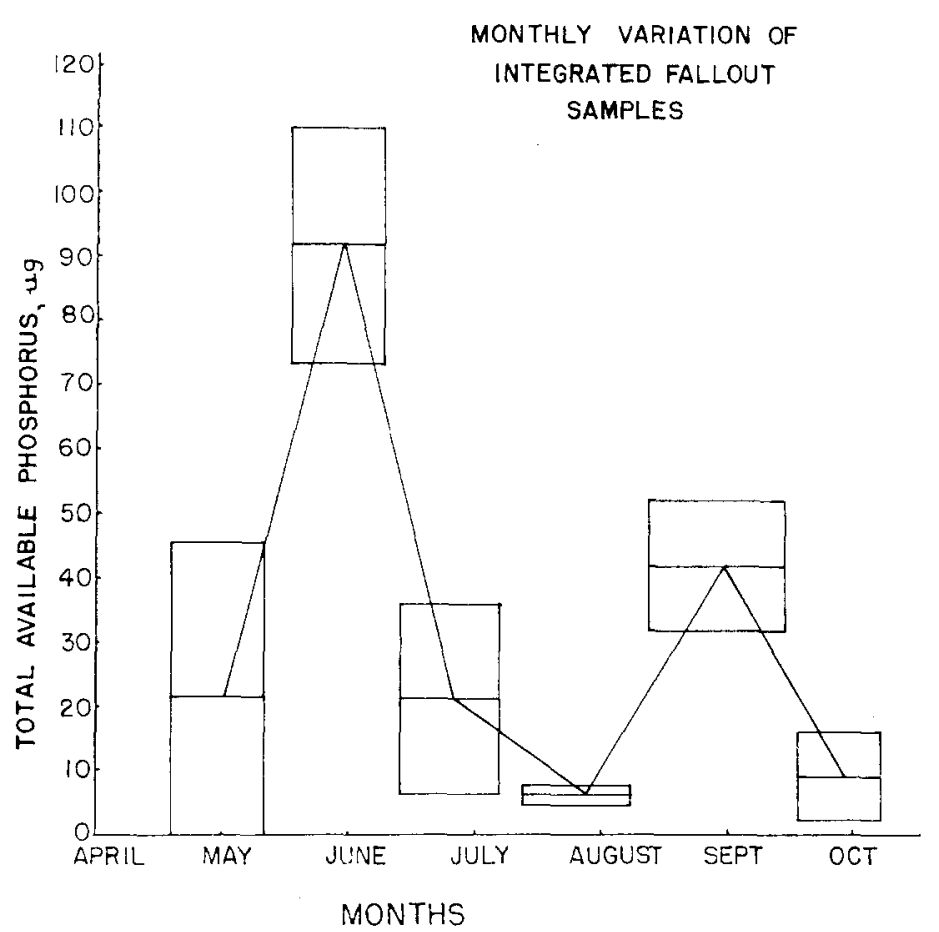

Fig. 2. Monthly variation of available $P$ in integrated fallout samples. The boxes indicate the $90 \%$ confidence limits for each monthly sample set.

found in the container by the time of exposure of the sample and the surface area of the collector. A mean value of $6.5 \mathrm{ng} \mathrm{cm}^{-2} \mathrm{day}^{-1}$ of available $P$ was observed for the months of April through October. A total of 225 metric tons of available $P$ would be predicted to enter southern Lake Huron (surface area $=9.5 \times 10^{13} \mathrm{~cm}^{2}$ ) on a yearly basis. Based on data for the fall samples for available-to-total $\mathrm{P}$ ratio, approximately 675 metric tons of $P$ per year would enter this portion of the lake.

\subsection{WET DEPOSITION}

Analysis of the event rain samples collected provided a means of determining the contribution of wet deposition to the total atmospheric $\mathrm{P}$ input to the lake. No rain events occurred during the sampling periods in April or May. Although there were few data points, the data for the remaining months indicated that a seasonal trend existed which was not that of the total fallout samples. The mean value of total soluble $\mathrm{P}$, in parts-per-billion, $90 \%$ confidence limit and number of samples collected for the months of June through October are: $7.09 \pm 3.05$, (5); 8.65, (1); 4.89 \pm 3.65 , (4); $0.95 \pm 0.13$, (4); and $1.96 \pm 4.00$, (3), respectively. Although these values represent only the soluble fraction of the available $\mathrm{P}$, it is still possible to estimate 
the contribution of precipitation to the integrated fallout samples. This value would be a lower limit, and the actual contribution is expected to be approximately double this value (Murphy, 1974). Figure 3 compares the temporal variation of the amount of available $P$ in the integrated samples, the concentration of soluble $P$ in the rainfall samples ( $\times 2$ approximately equals available $P$ ) and the rainfall in inches.

Using the above values as typical of the annual $P$ content of precipitation, input estimates were obtained by multiplying by the monthly rainfall from national weather service observation stations around the lake. From this data set, the wet deposition rate was calculated to be $1.1 \mathrm{ng} \mathrm{cm}^{-2} \mathrm{yr}^{-1}$ for soluble $\mathrm{P}$, or 76 metric ton $\mathrm{yr}^{-1}$ of available $\mathrm{P}$. The total $\mathrm{P}$ input from wet deposition would be approximately double this amount. This value agrees well with the value observed by Murphy and Doskey (1975) for $\mathrm{P}$ input to Lake Michigan from precipitation.

\subsection{DRY DEPOSITION}

A simple exponential falling box model was used to calculate the input of phosphorus to the Lake due to dry fallout. The assumptions made in such a model are: (1) A constant mixing height during the sampling period; (2) a complete sink at the bottom;

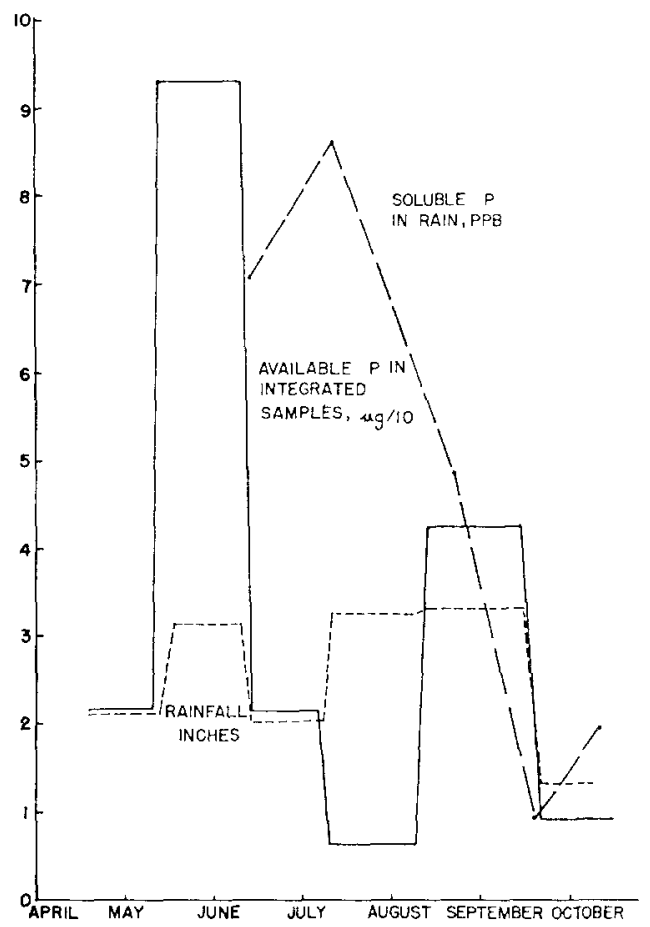

Fig. 3. Comparison of rainfall (inches), concentration of soluble $\mathbf{P}$ in rain (ppb) and amount of available $\mathrm{P}$ in integrated samples $(\mu \mathrm{g} / 10)$. 
(3) complete mixing of the components of the box; (4) no sources of the study material in the box; and (5) particles falling at some constant velocity. Under these conditions, the following equation applies:

$$
\log (C / C o)=\frac{V_{d} R_{t}}{H U},
$$

where $V_{d}=$ deposition velocity, $H=$ height of mixing layer, $C=$ downwind concentration, $C o=$ upwind concentration, $R_{t}=$ distance between sampling station, and $U=$ wind speed.

The height of the mixing layer was determined from aircraft data on back-scatter as a function of height; the concentrations upwind and downwind were determined from samples collected on the two shores; the distance between the samplers was known; and the wind speed was determined from national weather service data and from data obtained aboard the Roger R. Simons.

The size distribution of phosphorus-containing particles was determined each month from Andersen cascade impactor data. The mass median diameter for each month was found to be approximately $1 \mathrm{~cm}$ and the distribution was somewhat bimodal as shown in Figure 4. The size ranges for the stages $1-7$ are: $>4.6 \mu \mathrm{m}$, $2.9-4.6 \mu \mathrm{m}, 1.6-2.9 \mu \mathrm{m}, 0.9-1.6 \mu \mathrm{m}, 0.5-0.9 \mu \mathrm{m}, 0.3-0.5 \mu \mathrm{m}$, and $0.1-0.3 \mu \mathrm{m}$, respectively.

Of the 30 sampling periods in which the cross-lake wind vector allowed pairing of stations, 25 had $C / C o$ values less than unity. The remainder probably resulted from

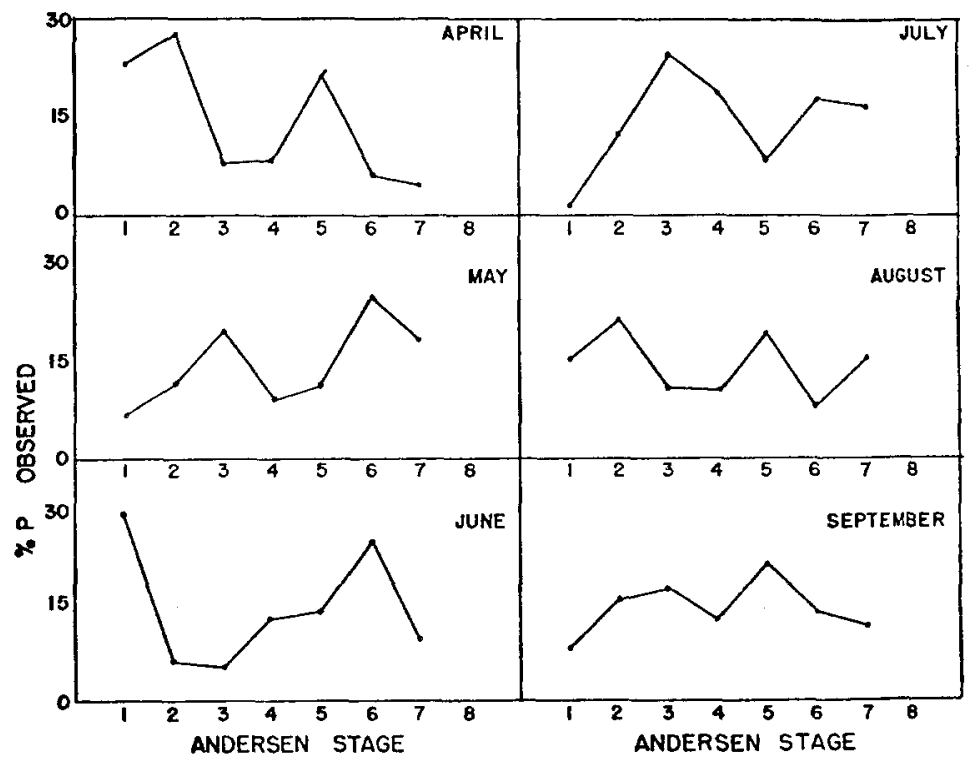

Fig. 4. Size distribution of $P$ in aerosol samples, 1975. 
elevation of the $\mathbf{P}$ due to sources in the vicinity of the downwind station. Solving the above equation for deposition velocity for each of the 25 cases, a value of $0.57 \pm 0.16 \mathrm{~cm} \mathrm{~s}^{-1}$ was obtained $(90 \%$ confidence). The deposition velocity assumed by Winchester and Nifong (1971) to estimate trace element inputs to Lake Michigan for particles in this size range was $0.5 \mathrm{~cm} \mathrm{~s}^{-1}$. The 'transfer efficiency', defined as the fraction of the upwind aerosol which enters the lake, was found to average approximately $30 \%$. This value was observed to vary inversely with windspeed. A value of $10 \%$ for the transfer efficiency of trace elements to Lake Michigan, originally estimated by Winchester and Nifong (1971), was later raised to $25 \%$ by Skibin (1973). To further compare the results of the present study with previous input measurements, deposition rate can be calculated by multiplying average aerosol concentration by deposition velocity: FLUX $=C_{\mathrm{AVE}} \times V_{\mathrm{D}}$. Based on HiVol data, the average total particulate loading in the basin area was found to be $28 \mu \mathrm{g}$ $\mathrm{m}^{-3}$. Using the deposition rate from the model, a deposition rate of $0.6-2.7 \mu \mathrm{g} \mathrm{cm}^{-2}$ day $^{-1}$ averaging $1.4 \mu \mathrm{g} \mathrm{cm}^{-2} \mathrm{day}^{-1}$ was found. Whelpdale (1974) obtained a value of $1.7 \mu \mathrm{g} \mathrm{cm}^{-2} \mathrm{day}^{-1}$ for samples collected in July 1968 . A yearly total input can be obtained from this deposition rate by multiplying by the surface area of southern Lake Huron $\left(9.5 \times 10^{13} \mathrm{~cm}^{2}\right)$. On this basis, 49000 metric tons of dry fallout were calculated to enter southern Lake Huron yearly.

To determine the potential impact of this impact on the lake, airborne particulate samples were analyzed for three fractions - water-soluble (soluble), acid $(\mathrm{pH}=2)$ soluble (reactive) and a third fraction which was not soluble in either water or acid, termed 'bound' $\mathrm{P}$. Of the total $\mathrm{P}$ in the aerosol, $29 \%$ was found to be water soluble and therefore immediately available to the biomass. Another $19 \%$ was acid soluble and therefore potentially available to the biomass. Thus over half of the $\mathbf{P}$ in the aerosol was found to be insoluble in both water and $\mathrm{H}_{2} \mathrm{SO}_{4}(\mathrm{pH}=2)$. This fraction must be present as either inorganic salts (insoluble metal phosphates) or as organically bound $\mathrm{P}$. While this $\mathrm{P}$ is not immediately available and probably settles to the bottom, it may eventually be released to the lake water through some aging process at the sediment-water interface.

TABLE II

Average monthly aerosol $\mathrm{P}$ concentration

\begin{tabular}{lcccc}
\hline $\begin{array}{l}\text { Sampling } \\
\text { period (1976) }\end{array}$ & $\begin{array}{l}\text { Soluble } \\
n g \mathrm{~m}^{-3} \mathrm{P}\end{array}$ & $\begin{array}{l}\text { Reactive } \\
\mathrm{ng} \mathrm{m}^{-3} \mathrm{P}\end{array}$ & $\begin{array}{c}\text { Available* } \\
\mathrm{ng} \mathrm{m}^{-3} \mathrm{P}\end{array}$ & $\begin{array}{l}\text { \% Soluble } \\
\text { of available }\end{array}$ \\
\hline $4 / 14-18$ & 54.7 & 50.3 & $105.1 \pm 19.0$ & 52.1 \\
$5 / 12-16$ & 56.9 & 29.2 & $86.1 \pm 16.6$ & 66.0 \\
$6 / 9-13$ & 12.6 & 6.5 & $19.5 \pm 3.5$ & 65.8 \\
$7 / 7-11$ & 1.8 & 5.8 & $7.6 \pm 2.1$ & 24.1 \\
$8 / 18-22$ & 4.3 & 3.7 & $8.1 \pm 1.9$ & 53.5 \\
$9 / 15-19$ & 14.0 & 5.1 & $19.1 \pm 2.1$ & 7.31 \\
$10 / 8-12$ & 8.0 & 3.6 & $11.6 \pm 2.1$ & 69.3 \\
\hline
\end{tabular}

$* 90 \%$ confidence limit. 
The seasonal variations of soluble, available and total $\mathrm{P}$ in the aerosol are shown in Table II and in Figure 5. The seasonal variation of the aerosol P is similar to both the integrated fallout samples (Figure 2) and the total aerosol loading. The rise in $\mathrm{P}$ input from all atmospheric sources in the Spring and Fall was previously suggested to be due to agricultural activity. The variation in the percent soluble of available $P$, also listed in Table II, tends to support this view. It may be that the addition of orthophosphate-enriched fertilizers increases the amount of water-soluble $P$, and the higher percentages observed in the Spring and Fall are due to increased aerosol injection of agricultural soil.

The $\mathrm{P}$ content of the aerosol varied from $<1$ to $369 \mathrm{ng} \mathrm{m}^{-3}$, with an 8 mo average of $76 \mathrm{ng} \mathrm{m}^{-3}$. From the model, the deposition rate for available $\mathrm{P}$ from dry fallout was calculated to be $1.7 \mathrm{ng} \mathrm{cm}^{-2}$ day $^{-1}$. On a yearly basis, 59 metric tons of available $\mathrm{P}$ and approximately 123 metric tons of total $\mathrm{P}$ would enter southern Lake Huron from dry fallout.

\section{Total and Relative Inputs of Phosphorus from Wet and Dry Deposition}

From the above data, total and relative inputs of $\mathbf{P}$ to southern Lake Huron can be determined by comparison of the average deposition rates of wet, dry and total fallout (Table III). On this basis, wet deposition accounts for $34 \%$ of the available $P$ in the integrated samples. Dry deposition accounts for another $26 \%$. The presence

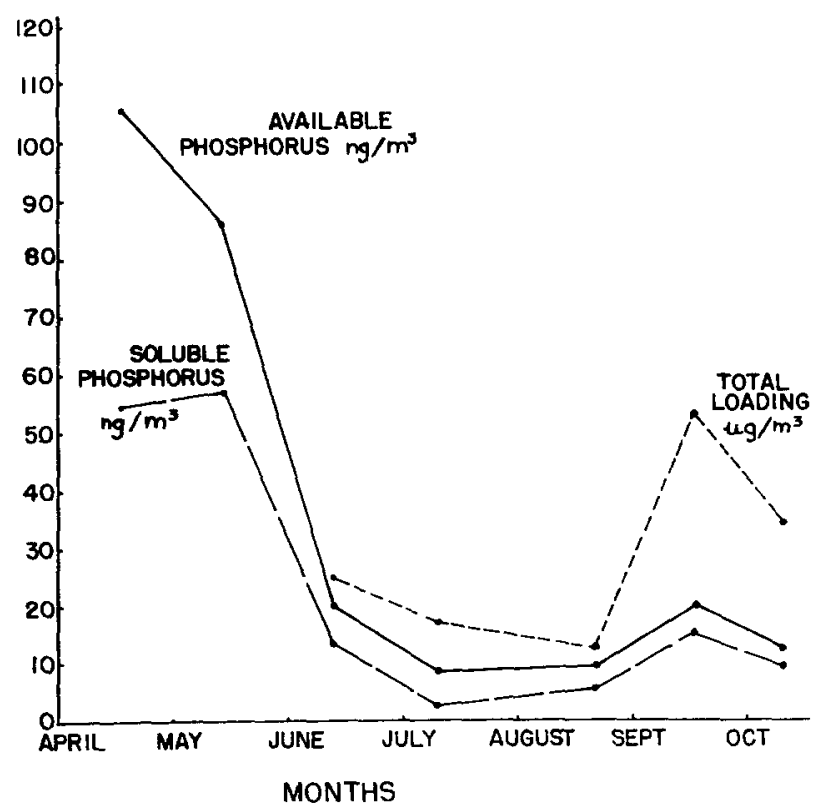

Fig. 5. Relationship between total aerosol concentration, soluble and available P. 
TABLE III

Deposition rates of available $\mathrm{P}$ for wet, dry, and integrated sampling techniques for the months of April-October, 1975

\begin{tabular}{|c|c|c|c|c|c|}
\hline $\begin{array}{l}\text { Sampling } \\
\text { period }\end{array}$ & $\begin{array}{l}\text { Wet* } \\
\text { deposition } \\
\text { ng } \mathrm{cm}^{-2} \text { day }^{-1}\end{array}$ & 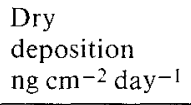 & $\begin{array}{l}\text { Integrated } \\
\text { deposition } \\
\operatorname{lng} \mathrm{cm}^{-2} \mathrm{day}^{-1}\end{array}$ & $\begin{array}{l}\% \text { Wet }{ }^{*} \text { of } \\
\text { integrated }\end{array}$ & $\begin{array}{l}\% \text { Dry of } \\
\text { integrated }\end{array}$ \\
\hline $4 / 18-5 / 12$ & - & $5.0 \pm 0.93$ & $5.2 \pm 5.8$ & - & 96 \\
\hline $5 / 16-6 / 9$ & - & $2.7 \pm 0.50$ & $23.1 \pm 4.6$ & - & 12 \\
\hline $6 / 13-7 / 7$ & $1.7 \pm 0.72$ & $0.69 \pm 0.31$ & $5.3 \pm 7.7$ & 32 & 13 \\
\hline $7 / 11-8 / 8$ & $1.5 \pm 1.1$ & $0.41 \pm 0.19$ & $1.0 \pm 0.22$ & $148(?)$ & 41 \\
\hline $8 / 12-9 / 15$ & $1.1 \pm 0.49$ & $0.71 \pm 0.12$ & $11.5 \pm 2.8$ & 9.6 & 6.2 \\
\hline $9 / 19-10 / 8$ & $0.1 \overline{2} \pm 0.13$ & $0.80 \pm 0.12$ & $2.9 \pm 2.2$ & 4.2 & 28 \\
\hline Average & $\begin{array}{l}1.1 \mathrm{ng} \\
\mathrm{cm}^{-2} \mathrm{day}^{-1}\end{array}$ & $\begin{array}{l}1.7 \mathrm{ng} \\
\mathrm{cm}^{-2} \mathrm{day}^{-1}\end{array}$ & $\begin{array}{l}6.5 \mathrm{ng} \\
\mathrm{cm}^{-2} \mathrm{day}^{-1}\end{array}$ & $15 \%$ & $33 \%$ \\
\hline
\end{tabular}

*Soluble portion only. Multiply by 2 to approximate available $\mathrm{P}$.

of biological material in the integrated fallout collectors would artificially raise the deposition rate of total fallout from the integrated samples. If the May-June integrated samples, which showed marked evidence of biological input, are eliminated, the wet-plus-dry inputs account for over $75 \%$ of the total available $\mathrm{P}$ observed. Biological events such as the spring bloom definitely result in an input to the lake but are local and restricted to nearshore regions. Thus the extrapolation of the deposition observed in integrated samples to a total lake input will be systematically high. This is also true if one considers total $\mathrm{P}$ rather than available $\mathrm{P}$. Analysis of September-December 1975 integrated fallout showed that available $\mathrm{P}$ was $32 \pm 16 \%$ of the total P observed.

On a yearly basis, 680 metric tons of $\mathrm{P}$ would be predicted to enter southern Lake Huron from the atmosphere, of which 150 metric tons can be accounted for by wet deposition and 120 metric tons by dry input. Thus only $40 \%$ of the total $\mathrm{P}$ input predicted from the integrated samples can be verified. Again, this discrepancy is believed to be due to biological and other local contamination of the integrated samples.

Another study of the atmospheric inputs of several elements to the Great Lakes was conducted by a team sponsored by the International Joint Commission (1977). The study areas for Lake Huron differed in that their work included an extra $3.7 \times 10^{13} \mathrm{~cm}^{2}$ of open Lake and the $2.8 \times 10^{13} \mathrm{~cm}^{2}$ of Saginaw Bay; and sampling relied primarily on integrated fallout collectors. In that study, atmospheric inputs of $P$ were found second only to tributary inputs from the state of Michigan in total tons of phosphorus per year. The IJC study estimated 450 metric ton $\mathrm{yr}^{-1}$ entering from the atmosphere. Correcting for the surface area differences, the IJC study would predict an input to southern Lake Huron of 270 metric ton $\mathrm{yr}^{-1}$. Despite errors due to inclusion of the industrialized area around Saginaw which would raise input estimates and the more remote northern regions which would have a lower input 
than the southern portion of the Lake basis, the agreement with the sum of wet and dry inputs is very good. It should be pointed out that the IJC summer data were modified on the basis of discussions with the present authors and that their input from bulk sample summer data was lowered on the basis of these discussions. Their raw data were consistent with our observation that bulk samplers provided high input estimates during the summer months.

\section{Conclusion}

The input of $\mathrm{P}$ to southern Lake Huron has been estimated. The contributions of wet and dry deposition have been shown to be approximately equal. The data from shore-based integrated fallout samples have been shown to give consistently higher results than the sum of wet and dry inputs. The significance of near-shore biological activity results in a higher input estimate when the deposition rate from integrated samples is extrapolated to the entire lake surface. It is likely that the actual input approaches the sum of the wet and dry depositions as described above.

\section{Acknowledgments}

This work was supported by the U.S. Environmental Protection Agency as part of a grant (No. R-803-086) to the Great Lakes Research Division of the University of Michigan. The support and assistance of these two organizations are gratefully acknowledged. Our thanks are also extended to James V. Murphy, Captain of the $\mathrm{R} / \mathrm{V}$ Roger $R$. Simons, and his crew for their help in collecting over-the-lake samples; to Chas. Fitzsimmons of the EPA-National Environmental Research Center, Las Vegas, Nevada, and his crew for collecting the aircraft samples; to C. Robert Snider of the U.S. Weather Service Forecast Office, Detroit Metropolitan Airport, for supplying the meteorological data; and to Dr. Edward S. Macias, Washington University, St. Louis, Missouri for assistance in the preparation of this manuscript. Details of the study may be found in the EPA report number $600-3 / 77-038$.

\section{References}

Delumyea, R. and Petel, R.: 1977, 'Atmospheric Input of Phosphorus to Southern Lake Huron AprilOctober, 1975'. EPA Report No. 600/3-77-038.

Elder, F. C.: 1975, 'International Joint Commission Program for Atmospheric Loading of the Upper Great Lakes'. Paper presented at Second Interagency Committee on Marine Science and Engineering Conference on the Great Lakes, Argonne, Ill.

International Joint Commission Report: 1977, 'The Waters of Lake Huron and Lake Superior. Volume II, [Part A]. Lake Huron, Georgian Bay and the North Channel.'

Menzel, D. W. and Corwin, N.: 1965, Limnol. Oceanogr. 10, 280.

Miller, W. E., Maloney, T. E., and Greent, J. C.: 1974, Water Res. 8, 667.

Murphy, J. and Riley, J. P.: 1962, Anal. Chim. Acta 27, 31.

Murphy, T. J.: 1974, 'Sources of phosphorus inputs from the atmosphere and their significance to oligotrophic lakes', Univ. Illinois, Urbana, Water Resources Research Center, Rep. No. 92.

Murphy, T. J. and Doskey, P. V.: 1975, EPA Report No. 600/3-75-005.

Schelske, C. L. \& Stoermer, E. F.: 1971, Science 173, 423.

Skibin, D.: 1973, Water Air Soil Pollut. 2, 405.

Whelpdale, D. M.: 1974, Water Air Soil Pollut. 3, 293.

Winchester, J. W. and Nifong, G. D.: 1971, Water Air Soil Pollut. 1, 50. 